\title{
EFFECT OF THERAPEUTIC TRAINING AND ACTIVE OUTPATIENT MANAGEMENT ON CLINICAL STATE AND CARDIOVASCULAR COMPLICATIONS IN PATIENTS WITH CHRONIC HEART FAILURE (THREE YEAR FOLLOW-UP)
}

\author{
A.P. Rebrov, N.A. Kosheleva* \\ Saratov State Medical University named after V.I. Razumovsky. Bolshaya Kazachya 112, Saratov, 410012 Russia \\ Effect of therapeutic training and active outpatient management on clinical state and cardiovascular complications in patients with chronic heart failure (three year follow-up) \\ A.P. Rebrov, N.A. Kosheleva* \\ Saratov State Medical University named after V.I. Razumovsky. Bolshaya Kazachya 112, Saratov, 410012 Russia
}

Aim. To evaluate effect of therapeutic training and active outpatient management on clinical state and cardiovascular complications (CVC) in patients with chronic heart failure (CHF) during three year follow-up.

Material and methods. A total of 211 patients with CHF experienced Q-wave myocardial infarction were enrolled in the study. At admission to the hospital all patients were randomized into two groups. Patients of the first group (group 1; $\mathrm{n}=106$ ) were managed actively after discharge from the hospital, patients of the second group (group 2; $\mathrm{n}=105$ ) - managed conventionally after discharge from the hospital. In the hospital patients of the both groups were therapeutically trained and treated according to contemporary guidelines. Patients were observed for three years.

Results. Over three year follow-up actively managed patients demonstrated significant $(p<0.05)$ decrease in systolic and diastolic blood pressure, heart rate, blood serum levels of total cholesterol and $\mathrm{N}$ terminal prohormone of brain natriuretic peptide (NT-proBNP), augmentation of 6 -minute walk-test distance, deceleration of heart remodeling and left ventricle ejection fraction reduction as compared to those who were conventionally managed. Kaplan-Meier curves revealed that risk of CHF decompensation $(p=0.001)$, mortality $(p=0.04)$, and total number of CVC ( $p=0.04)$ was significantly lower in the first group than this in the second one.

Conclusion. Therapeutic training and active outpatient management in patients with CHF improves patient compliance to pharmacotherapy, their clinical state and outcomes.

Key words: chronic heart failure, therapeutic training, outpatient follow-up, cardiovascular complications.

Rational Pharmacother. Card. 2011;7(3):275-287 Влияние терапевтического обучения и активного амбулаторного ведения пациентов с ХСН на их клиническое состояние и сердечно-сосудистые осложнения (трехлетнее наблюдение)
А.П. Ребров, Н.А. Кошелева*

Саратовский государственный медицинский университет им. В.И. Разумовского. 410012, Саратов, ул. Б. Казачья, 112

Цель. Оценить влияние терапевтического обучения и активного амбулаторного ведения на клиническое состояние и развитие сердечно-сосудистых осложнений (ССО) у больных хронической сердечной недостаточностью (ХСН) в течение трех лет наблюдения.

Материал и методы. В исследование были включены 211 больных XСН, развившейся после перенесенного инфаркта миокарда с зубцом Q на ЭКГ. При поступлении в стационар все пациенты были рандомизированы в две группы: группа 1 ( $n=106$ пациентов) - группа активного амбулаторного ведения; группа 2 ( $n=105$ больных) - группа стандартного амбулаторного ведения. Все больные прошли терапевтическое обучение и получали терапию в соответствии с современными рекомендациями. Период амбулаторного (постгоспитального) наблюдения составил 3 года. Результаты. В течение трех лет наблюдения в группе пациентов активного ведения отмечалось значимое $($ р $<0,05)$ снижение систолического и диастолического артериального давления, частоты сердечных сокращений, уровней общего холестерина, N-терминального фрагмента мозгового натрийуретического пептида (NT-рroBNP), прирост дистанции теста 6 -минутной ходьбы, замедление процессов ремоделирования сердца и снижения фракции выброса левого желудочка по сравнению с больными группы стандартного ведения. При построении кривых КапланаМейера установлено, что у пациентов группы активного ведения к третьему году наблюдения вероятность развития декомпенсации XCH ( $p=0,001)$, летального исхода ( $p=0,04)$, общего числа ССО $(p=0,04)$ значимо меньше, чем у пациентов при стандартном ведении.

Заключение. Обучение и активное трехлетнее амбулаторное ведение больных ХСН способствовало повышению приверженности пациентов медикаментозной терапии, улучшению клинического состояния больных и улучшению прогноза.

Ключевые слова: хроническая сердечная недостаточность, терапевтическое обучение, амбулаторное наблюдение, сердечно-сосудистые осложнения.

РФК 2011;7(3):275-287

*Corresponding author (Автор, ответственный за переписку): kosheleva2009@yandex.ru

Chronic heart failure (CHF) epidemiologic studies recently completed in Western Europe and the USA demonstrated still high one-year mortality (about $30 \%$ ) in this group of patients despite the implementation of effective drugs in clinical practice such as ACE inhibitors (ACEi) and $\beta$-blockers [1-3]. This may be due to low patients' compliance to the prescribed therapeutic regime, diet and life mode.

Programmes of CHF treatment including patients' and their relatives' training have become useful in improvement of quality of life in these patients [4]. This training is focused on informing patients and their relatives about the CHF symptoms, self-control skills, dietary advices, physical activity and
Эпидемиологические исследования последних лет, включавшие больных хронической сердечной недостаточностью $(\mathrm{XCH})$ в Западной Европе и США, показали, что, несмотря на внедрение во врачебную практику эффективных лекарственных средств [ингибиторы АПФ (иАПФ) и бета-адреноблокаторы (БАБ)], однолетняя смертность больных в этой популяции остается по-прежнему высокой, достигая 30\% в год [1 -3]. Среди возможных причин этого явления особая роль отводится низкой приверженности пациентов предписанному терапевтическому режиму и отсутствию строгого выполнения врачебных рекомендаций, касающихся диеты и образа жизни.
Authors' information:

Andrey P. Rebrov - Ph.D., MD, Professor, Head of Chair of Hospital Therapy, Saratov State Medical University named after V.I. Razumovsky

Natalia A. Kosheleva - Ph.D., MD, Assistant of the same chair
Сведения об авторах:

Ребров Андрей Петрович - д.м.н., профессор, заведующий кафедрой госпитальной терапии Саратовского ГМУ им. В.И. Разумовского

Кошелева Наталья Анатольевна - К.М.Н., ассистент той же кафедры 
pharmacotherapy regime [5]. Therefore, the preferred direction in CHF management is not so much the search for new treatment methods as adequate application of current high efficiency therapeutic facilities. At the present day there is no lack of programmes which confirm the efficacy of therapeutic training and active outpatient management. However, duration of most of them was less than a year [6-8]. More longterm observations are rather rare.

The aim of the study was to evaluate effect of therapeutic training and active outpatient management on clinical state and cardiovascular complications (CVC) in patients with CHF due to ischemic heart disease (IHD) during three year follow-up.

\section{Material and methods}

A total of 211 patients with CHF experienced Q-wave myocardial infarction were enrolled in the open prospective randomized study which was performed at the base of cardiology department of Saratov region clinical hospital from 2007 up to 2010 years.

The inclusion criteria were as follows:

- CHF symptoms (functional class (FC) I-IV) manifested after Q-wave myocardial infarction,

- patient informed consent to the study.

The exclusion criteria were: unstable angina and myocardial infarction during the last three months before the study, serum creatinine $>177 \mathrm{umol} / \mathrm{L}(2 \mathrm{mg} / \mathrm{dl})$, aspartate- and alanine-aminotransferase more than twofold increase, exacerbation of chronic diseases, contraindications to ACEi prescription.

At hospital admission all of the patients were randomized in two groups by the method of random numbers: group of the active management ( $n=106)$ - group 1 and group of the conventional management $(n=105)$ - group 1. Training of the first group patients included: group session in "School for CHF patients", two 30 -minute one-to-one lessons, outpatient follow-up by phone contacts with the following frequency: once a fortnight during the first month after discharge from the hospital and then - once a month. During phone contacts patient's state was estimated and treatment recommendations were given. Pharmacotherapy was defined in accordance to National guidelines for $\mathrm{CHF}$ diagnostics and treatment. Training of the second group patients included group session in "School for CHF patients" and two 30-minute one-to-one lessons. After the hospital discharge these patients were recommended to keep on ACEi intake (as part of composite therapy) and to be under follow-up in a residential outpatient clinic.

The follow-up period was three years. During this period patients had four visits to doctor: the first initiating visit (start of the follow-up), the second intermediate visit ( 1 year later), the third intermediate visit ( 2 years later) and the forth final one (3 years later).
Одним из эффективных методов улучшения качества лечения пациентов с ХСН стали «Программы лечения сердечной недостаточности», важнейшей задачей которых является обучение пациентов и их родственников [4]. Целью обучения является помощь пациентам и их родным в получении информации о заболевании, приобретении навыков самоконтроля, касающихся диетических рекомендаций, физической активности, строгого соблюдения режима медикаментозной терапии, наблюдения за симптомами ХCH и обращения за медицинской помощью в случае их усиления [5]. В связи с этим приоритетным научным направлением по проблеме XCH является не столько поиск новых методов лечения, сколько использование в полном объеме современных подходов, адекватного применения уже существующих высокоэффективных терапевтических возможностей. В настоящее время имеется достаточное число программ, подтверждающих эффективность терапевтического обучения и активного амбулаторного наблюдения, большинство из них длительностью не более года [6-8]. Опыта более продолжительных наблюдений существенно меньше.

Цель исследования - оценка влияния терапевтического обучения и активного амбулаторного ведения на клиническое состояние и развитие сердечнососудистых осложнений у больных ХСН, осложнившей течение ишемической болезни сердца в течение трех лет наблюдения.

\section{Материал и методы}

В открытое проспективное рандомизированное исследование, проводимое на базе кардиологического отделения Саратовской областной клинической больницы с 2007 по 2010 гг., были включены 211 больных с постинфарктным кардиосклерозом с симптомами XСH.

Критерии включения:

- наличие симптомов XCH (I-IV функционального класса, ФК), развившихся после перенесенного инфаркта миокарда (ИМ) с зубцом Q на ЭКГ;

- информированное согласие пациента.

Критерии исключения: нестабильная стенокардия и инфаркт миокарда в течение последних 3-х месяцев перед исследованием, креатинин сыворотки более 177 мкмоль/л (2 мг/дл), повышение уровня аспарагиновой и аланиновой трансаминаз более 2 норм, хронические заболевания в фазе обострения, противопоказания к назначению иАПФ.

При поступлении в стационар все пациенты методом случайных чисел были рандомизированы в две группы: группа 1 ( $n=106)$ - группа активного ведения; группа $2(n=105)$ - группа стандартного ведения. Пациенты первой группы проходили обучение, включающее групповое занятие в «Школе больных ХСН», два 
The following evaluations and measurements were performed in all patients during the visits: functional heart reserve (6-minute walk-test [9]); CHF FC by NYHA; morphofunctional heart characteristics; blood serum levels of supersensitive C-reactive protein (SsCRP) and N-terminal prohormone of brain natriuretic peptide (NT-proBNP); lipid blood profile; creatinine serum levels with glomerular filtration rate (GFR) calculation by MDRD [10]; blood pressure (BP) and heart rate (HR).

The following end points were recorded during the follow-up: CHF exacerbation which demanded hospitalization; unstable angina or myocardial infarction occurrence; lethal outcome; the total amount of CVC. End points were analyzed on the base of information received from the patients and their relatives, discharge epicrisises, autopsy conclusions.

Echocardiography with routine indices estimation [11] was performed with Acuson 128 XP/10. SsCRP was detected with Diasys company (Germany) test kits. NT-proBNP level was detected by enzymoimmunoassay with Biomedica company (Slovakia) test kits.

Statistical analysis was performed with Statistica 8.0 software package. Distribution parameters were analyzed by Kolmogorov-Smirnov test. Data are presented in $\mathrm{M} \pm \mathrm{SD}$ (mean \pm standard deviation) for parametric distribution and in Me [10\%;90\%] (median [10th and 90th percentiles]) for nonparametric one. For independent (unconjugated) samples comparison Student's t-test and Mann-Whitney $U$-test were used. To evaluate effects of different patient management tactics on CVC rate Kaplan-Meier survival curves were plotted, distinctions significance was estimated by Log-rank test. Distinctions were considered as significant at $p<0.05$.

\section{Results}

Patients of the both groups were matched by the sex, age, amount of smokers, number of experienced myocardial infarctions, CHF duration and FC, 6 - minute walk-test distance, FC of stable angina pectoris, prevalence of arterial hypertension (HT) and diabetes mellitus, body mass index (BMI), systolic and diastolic BP levels (SBP and DBP), HR, number of angina episodes and nitroglycerin taking need per week, left ventricle ejection fraction (LV EF), cholesterol and NT-proBNP levels (Table 1).

A total of 106 patients (100\%) of the first group were examined one year later, 100 patients (94.3\%) - two years later and $78(73.6 \%)$ - three years later. As for the second group: 103 patients (98.1\%) were examined one year later, $87(82.6 \%)$ - two years later and 60 (57.1\%) - three years later. The contact with the other patients was lost.

Taking into account significant prognostic value of CHF patients' compliance to prescribed treatment mode we analyzed the frequency of prescription and intake of the main groups of drugs within three year follow-up. индивидуальных занятия по 30 минут, амбулаторное наблюдение посредством телефонных контактов со следующей регулярностью: первый мес после выписки из стационара - 1 раз/2 нед, далее - 1 раз/мес. При телефонном контакте оценивались состояние больного, проводимая терапия, давались рекомендации по лечению. Медикаментозная терапия всем больным назначалась в соответствии с Национальными рекомендациями по диагностике и лечению XCH.

Пациенты второй группы проходили обучение, включающее групповое занятие в «Школе больных ХСН» и два индивидуальных занятия по 30 мин. После выписки из кардиологического отделения этим больным было рекомендовано в составе комплексной терапии продолжить прием иАПФ и наблюдение в условиях поликлиники по месту жительства.

Период наблюдения составил 3 г., в течение которых были проведены 4 визита: визит 1 - инициирующий (начало наблюдения); визит 2 - промежуточный (1 год); визит 3 - промежуточный (2 года); визит 4 - заключительный (3 года).

Во время визитов всем больным проводилась оценка функционального резерва (тест с 6 -минутной ходьбой [9]) с определением ФК ХСН (по классификации Нью-Йоркской Ассоциации сердца в модификации Общества специалистов по сердечной недостаточности 2002 г) и морфофункциональных параметров сердца, уровней высокочувствительного C-реактивного белка (ВчСРБ) и N-терминального фрагмента мозгового натрийуретического пептида (NT-proBNP), исследование липидного спектра крови, креатинина и расчет скорости клубочковой фильтрации (СКФ) по MDRD [10], а также измерение артериального давления (АД) и частоты сердечных сокращений (ЧСС).

За время наблюдения фиксировались следующие конечные точки: ухудшение течения ХCH, потребовавшее госпитализации; развитие нестабильной стенокардии и инфаркта миокарда; летальный исход; общее количество сердечно-сосудистых осложнений (ССО). Анализ конечных точек проводился на основании данных, полученных от больных и их родственников, выписок из историй болезни, из патологоанатомических заключений и справок о смерти.

Эхокардиография (ЭхоКГ) выполнялась на комплексе Acuson 128 XP/10 с определением стандартных показателей [11]. Высокочувствительный С-реактивный белок определяли с помощью реактивов фирмы Diasys (Германия). Уровень NT-proBNP определяли иммуноферментным методом с помощью реактивов фирмы Biomedica (Словакия).

Статистическая обработка полученных данных проводилась с использованием пакета программ Statistica 8.0. Тестирование параметров распределения проводили с помощью критерия Колмогорова-Смирнова. При па- 
Table 1. Initial clinical characteristics of CHF patients in the groups of active and conventional management

Таблица 1. Исходная клиническая характеристика больных ХСН в группах активного и стандартного ведения

\begin{tabular}{|c|c|c|}
\hline $\begin{array}{l}\text { Index } \\
\text { Показатель }\end{array}$ & $\begin{array}{l}\text { Group } 1 \\
\text { Группа } 1 \\
(n=106)\end{array}$ & $\begin{array}{l}\text { Group } 2 \\
\text { Группа } 2 \\
(n=105)\end{array}$ \\
\hline $\begin{array}{l}\text { Gender (men) } \\
\text { Пол (мужчины), n (\%) }\end{array}$ & $90(85)$ & $93(88)$ \\
\hline $\begin{array}{l}\text { Age, years } \\
\text { Возраст, годы }\end{array}$ & $56.0[47 ; 66]$ & $56.0[45 ; 68]$ \\
\hline $\begin{array}{l}\text { Smoking } \\
\text { Курение, n (\%) }\end{array}$ & $55(52)$ & $56(53)$ \\
\hline $\begin{array}{l}\text { Number of experienced Ml per patient } \\
\text { Количество перенесенных } \\
\text { ИМ у одного больного } \\
\end{array}$ & $1.0[1.0 ; 2.0]$ & $1.0[1.0 ; 2.0]$ \\
\hline $\begin{array}{l}\text { CHF duration, years } \\
\text { Длительность XСН, годы }\end{array}$ & $3.0[0.5 ; 8]$ & $3.0[0.5 ; 9.0]$ \\
\hline $\begin{array}{l}\text { Stable angina pectoris, FC } \\
\text { Стабильная стенокардия, ФК }\end{array}$ & $3[3 ; 4]$ & $3[3 ; 4]$ \\
\hline $\begin{array}{l}\mathrm{HT} \\
\mathrm{A} \Gamma, n(\%)\end{array}$ & $94(87)$ & $91(87)$ \\
\hline $\begin{array}{l}\text { HT duration, years } \\
\text { Длительность АГ, годы }\end{array}$ & $8.0[1 ; 26]$ & $7.0[1 ; 24]$ \\
\hline $\begin{array}{l}\text { Diabetes mellitus } \\
\text { Сахарный диабет, n (\%) }\end{array}$ & $24(23)$ & $21(20)$ \\
\hline $\begin{array}{l}\mathrm{BMI}, \mathrm{kg} / \mathrm{m} 2 \\
\text { ИMT, } \mathrm{k \Gamma} / \mathrm{M} 2\end{array}$ & $29.1 \pm 4.7$ & $29.6 \pm 6.1$ \\
\hline $\begin{array}{l}\text { SBP, mm Hg } \\
\text { САД, мм рт.ст. }\end{array}$ & $120[110 ; 150]$ & $120[110 ; 150]$ \\
\hline $\begin{array}{l}\text { DBР, mm Hg } \\
\text { ДАД, мм рт.ст. }\end{array}$ & $80[70 ; 90]$ & $80[70 ; 90]$ \\
\hline $\begin{array}{l}\mathrm{HR} \text { bt/min } \\
\text { ЧСС, УД/МИн }\end{array}$ & $70[60 ; 88]$ & $72[60 ; 90]$ \\
\hline $\begin{array}{l}\text { 6-min walk-test distance, m } \\
\text { Дистанция 6-мин теста, м }\end{array}$ & $300[100 ; 500]$ & $300[100 ; 500]$ \\
\hline $\begin{array}{l}\text { NYHA FC / ФK NYHA, n (\%) } \\
\text { II } \\
\text { III } \\
\text { IV }\end{array}$ & $\begin{array}{l}15(14.2) \\
25(23.5) \\
44(41.5) \\
22(20.8)\end{array}$ & $\begin{array}{l}13(12.4) \\
27(25.7) \\
45(42.8) \\
20(19)\end{array}$ \\
\hline $\begin{array}{l}\mathrm{LVEF} \\
\text { ФВ ЛЖ, \% }\end{array}$ & $40.4 \pm 7.5$ & $39.8 \pm 7.4$ \\
\hline $\begin{array}{l}\mathrm{TCS}, \mathrm{mmol} / \mathrm{l} \\
\text { OХС, ммоль/л }\end{array}$ & $5.6 \pm 1.4$ & $5.5 \pm 1.3$ \\
\hline $\begin{array}{l}\text { NT-proBNP, pg/ml } \\
\text { ПГ/МЛ }\end{array}$ & $110[90 ; 380]$ & $110[90 ; 400]$ \\
\hline $\begin{array}{l}\mathrm{SsCRP}, \mathrm{g} / \mathrm{I} \\
\mathrm{BчCPБ,} \mathrm{Г/ת}\end{array}$ & $1.4[0.7 ; 8.8]$ & $1.4[0.7 ; 9.1]$ \\
\hline \multicolumn{3}{|c|}{ 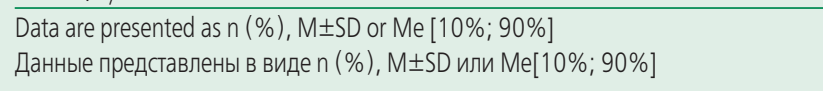 } \\
\hline \multicolumn{3}{|c|}{$\begin{array}{l}\text { MI-myocardial infarction, HT-arterial hypertension, BMI-body mass index, } \\
\text { SBP-systolic BP, DBP-diastolic BP, HR-heart rate, FC-functional class, LV EF-left } \\
\text { ventricle ejection fraction, TCS-total cholesterol, SSCRP-supersensitive } \\
\text { C-reactive protein }\end{array}$} \\
\hline \multicolumn{3}{|c|}{$\begin{array}{l}\text { ИМ-инфаркт миокарда, АГ-артериальная гипертония, ИМТ-индекс массы } \\
\text { тела, САД-систолическое АД, ДАД-диастолическое АД, ЧСС-частота сердечных } \\
\text { сокращений, ФК-функциональный класс, ФВ ЛЖ-фракция выброса левого } \\
\text { желудочка, ОХС-общий холестерин, ВчСРБ-высокочувствительный } \\
\text { С-реактивный белок }\end{array}$} \\
\hline
\end{tabular}

раметрическом характере распределения данные представлены в виде $\mathrm{M} \pm \mathrm{SD}$ (среднее \pm среднее квадратическое отклонение), при непараметрическом распределении переменные представлены в виде Ме [10\%;90\%] (медиана [10-й и 90-й процентили]). Для сравнения двух несвязанных групп использовали tкритерий Стьюдента, критерий Манна-Уитни. Для определения влияния различных способов ведения больных на развитие ССО были построены кривые времени наступления неблагоприятных событий (Каплана-Мейера) с анализом достоверности различий про помощи теста Log-rank. Различия считали значимыми при p<0,05.

\section{Результаты}

Пациенты обеих групп были сопоставимы по полу, возрасту, числу курильщиков, количеству перенесенных инфарктов миокарда, длительности проявлений и ФК ХСН, дистанции 6-мин теста, ФК стабильной стенокардии, встречаемости артериальной гипертензии, количеству больных сахарным диабетом, индексу массы тела (ИМТ), уровням систолического (САД) и диастолического АД (ДАД), ЧСС, числу эпизодов стенокардии и еженедельной потребности в нитроглицерине, фракции выброса левого желудочка (ФВ ЛЖ), уровню холестерина и NT-proBNP (табл. 1).

В группе 1 динамическое обследование осуществлено у 106 (100\%) больных через год, у 100 (94,3\%) пациентов через два года, у 78 (73,6\% ) обследуемых через три года. Во второй группе обследование проведено у 103 (98,1\%) больных через год, у 87 (82,6\% ) пациентов через два года, у 60 (57,1\%) больных через три года. Контакт с остальными обследуемыми был утерян.

Учитывая важное прогностическое значение приверженности пациентов XСН назначенному терапевтическому режиму, проанализирована частота назначения и приема основных групп лекарственных препаратов в течение трех лет наблюдения.

Частота назначения и приема препаратов основных лекарственных классов больными ХСН в группах активного и стандартного ведения при наблюдении представлена в табл. 2.

Пациентам обеих групп назначали иАПФ/антагонисты рецепторов ангиотензина II (АРА ІІ) в 100\% случаев. В первой группе исходно БАБ принимали 102 $(96,2 \%)$ больных; антагонисты альдостерона - 85 $(80,1 \%)$; диуретики (фуросемид, торасемид, гидрохлортиазид) - 27 (25,4\%); статины - 102 (96,2\%) пациента. Во второй группе исходно БАБ принимали 100 $(95,2 \%)$ пациента; антагонисты альдостерона - 84 (80\%) больных; мочегонные - 26 (24,7\%) обследуемых и статины - 100 (95,2\%) наблюдаемых. Исходно БАБ не применялись у 6 больных из-за брадикардии и у 3 пациентов из-за артериальной гипотензии. Статины в стационаре не получали трое больных 
The table 2 demonstrates frequency of drugs prescription and intake in the groups of active and conventional managements during follow-up.

Patients of the both groups were prescribed ACEi or angiotensin-II receptor antagonists (ARA) in $100 \%$ of cases. Initially in the first group 102 (96.2\%) patients received B-blockers, 85 (80.1\%) - aldosterone antagonists, 27 (25.4\%) - diuretics (furosemide, torasemide, hydrochlorothiazide) and 102 (96.2\%) patients - statins. In the second group there were 100 (95.2\%) patients who received $\beta$-blockers, 84 ( $80 \%$ ) - aldosterone antagonists, $26(24.7 \%)$ - diuretics and 100 (95.2\%) - statins. Six patients were not prescribed $\beta$-blockers because of bradycardia and three ones - because of arterial hypotension. Three patients did not receive statins in the hospital because of allergic reaction (urticaria) and five ones had hepatic function impairment which limited statins use.

Within three year follow-up more than $90 \%$ of patients in the first group permanently received ACEi/ARA and $\beta$-blockers. Aldosterone antagonists were used by $70 \%$ of patients. Share of patients in the first group who received diuretics had increased from $25 \%$ up to $29 \%$ to the third year of the follow-up. Despite treatment training and monthly control only $65 \%$ of patients received statins within the first two years and $61.5 \%$ - within the third year of the follow-up.

Patients of the first group received the following ACEi: lisinopril $-70 \%$, perindopril - 10\%, enalapril - 10\%, monopril $-5 \%$; ARA (candesartan, valsartan) $-5 \%$ of cases. At the same time they received the following $\beta$-blockers: bisoprolol $-50 \%$, carvedilol $-30 \%$, metoprolol $-20 \%$ of cases. The average dose of verospiron was $50 \mathrm{mg} /$ day. Patients of the first group also received diuretics: furosemide - $50 \%$, torasemide $-30 \%$, hydrochlorothiazide $-20 \%$ of cases. A number of torasemide treated patients had increased up to $60 \%$ by the third year of the follow-up. Among statins simvastatin and atorvastatin were prescribed in $40 \%$ and $60 \%$ of patients, respectively.

Decrease in the main neurohormonal modulators and statins intake was observed in patients of the second group. By the third year of the follow-up ACEi/ARA were received only by 32 (53.3\%) patients, $\beta$-blockers - by 35 (58.3\%), из-за аллергической реакции по типу крапивницы на эти препараты и 5 пациентов имели нарушение функции печени, ограничивающее их применение.

В течение трех лет в группе 1 иАПФ/АРА II и БАБ постоянно принимали более $90 \%$ больных. В этой группе не менее 70\% пациентов в своем лечении использовали антагонисты альдостерона. Удельный вес больных первой группы, принимающих диуретики, увеличился с 25\% до 29\% только к третьему году наблюдения. Несмотря на терапевтическое обучение и ежемесячный контроль, статины принимали только 65\% пациентов в первые два года и 61,5\% больных в течение третьего года наблюдения.

В течение наблюдения пациенты группы 1 принимали следующие иАПФ: лизиноприл - 70\%, периндоприл - 10\%, эналаприл - 10\%, моноприл - 5\%; APA II (кандесартан, валсартан) - 5\%. За это же время больные принимали следующие БАБ: бисопролол - 50\%; карведилол - 30\%; метопролол - 20\%. Средняя доза верошпирона составила 50 мг/сут. Из диуретиков обследуемые получали фуросемид - 50\%; торасемид - 30\%; гидрохлортиазид - 20\%. К третьему году наблюдения увеличилось число пациентов, принимающих торасемид до 60\%. Из статинов пациенты принимали симвастатин в $60 \%$ случаев, аторвастатин в 40\%.

В группе 2 отмечено снижение частоты приема основных нейро-гормональных модуляторов и статинов. Ингибиторы АПФ/АРА II к третьему году наблюдения принимали 32 (53,3\%) пациента, БАБ - 35 (58,3\%) больных, антагонисты альдостерона - $37(47,4 \%)$ пациентов, статины - 21 (35\%) больных. Диуретики на протяжении трех лет наблюдения принимали около 30\% пациентов.

За время наблюдения пациенты группы 2 принимали следующие ингибиторы АПФ/АРА ІІ: эналаприл $55 \%$, периндоприл - 20\%, лизиноприл - 15\%, моноприл - 10\%. Обследуемые пациенты принимали следующие бета-блокаторы: бисопролол - 40\%, акридилол $-25 \%$, метопролол $-25 \%$, атенолол $-10 \%$. Средняя доза верошпирона составила 50 мг/сут. Из мочегонных препаратов обследуемые группы стандартного ведения получали фуросемид - 70\%, диувер

Table 2. Frequency of drugs prescription and taking by CHF patients in the groups of active and conventional management

Таблица 2. Частота назначения и приема препаратов больными ХСН в группах активного и стандартного ведения

\begin{tabular}{|c|c|c|c|c|c|c|c|c|}
\hline \multirow{2}{*}{$\begin{array}{l}\text { Drugs group } \\
\text { Группа препаратов }\end{array}$} & \multicolumn{4}{|c|}{ Group 1 / Группа 1} & \multicolumn{4}{|c|}{ Group 2 / Группа 2} \\
\hline & $\begin{array}{l}\text { Initially } \\
\text { Исходно }\end{array}$ & $\begin{array}{l}\text { 1-st year } \\
1 \text { rод }\end{array}$ & $\begin{array}{l}\text { 2-d year } \\
2 \text { года }\end{array}$ & $\begin{array}{l}\text { 3-d year } \\
3 \text { rода }\end{array}$ & $\begin{array}{l}\text { Initially } \\
\text { Исходно }\end{array}$ & $\begin{array}{l}\text { 1-st year } \\
1 \text { год }\end{array}$ & $\begin{array}{l}\text { 2-d year } \\
2 \text { года }\end{array}$ & $\begin{array}{l}\text { 3-d year } \\
3 \text { года }\end{array}$ \\
\hline ACEi/ARA / иАПФ/APA II, n (\%) & $106(100)$ & $101(95.2)$ & $92(92)$ & $72(92.3)$ & $105(100)$ & $78(75.7)$ & $60(68.9)$ & $32(53.3)$ \\
\hline$\beta$-blockers / БАБ, n (\%) & $102(96.2)$ & $102(96.2)$ & $92(92)$ & $72(92.3)$ & $105(100)$ & $78(75.7)$ & $60(68.9)$ & $32(53.3)$ \\
\hline $\begin{array}{l}\text { Aldosterone antagonists } \\
\text { антагонисты альдостерона, n (\%) }\end{array}$ & $85(80.1)$ & $78(73.5)$ & $72(72)$ & $56(71.7)$ & $84(80)$ & $72(67.9)$ & $61(61)$ & $37(47.4)$ \\
\hline Diuretics / диуретики, n (\%) & $27(25.4)$ & $25(25.4)$ & $26(26)$ & $23(29.4)$ & $26(24.7)$ & $30(29.1)$ & $25(28.7)$ & $18(30)$ \\
\hline Statins / статины, n (\%) & $102(96.2)$ & $69(65)$ & $65(65)$ & $48(61.5)$ & $100(95.2)$ & $49(47.5)$ & $41(47.1)$ & $21(35)$ \\
\hline
\end{tabular}


aldosterone antagonists - by 37 (47.4\%) and statins - by $21(35.0 \%)$ patients. About $30 \%$ of the patients received diuretics within three year follow-up.

Patients of the second group received the following ACEi: enalapril $-55 \%$, perindopril $-20 \%$, lisinopril $-15 \%$, monopril $-10 \%$ and $\beta$-blockers: bisoprolol $-40 \%$, carvedilol $-25 \%$, metoprolol $-25 \%$, atenolol $-10 \%$. The average verospiron dose was $50 \mathrm{mg} /$ day. Patients of the conventionally managing group received the following diuretics: furosemide $-70 \%$, torasemide $-10 \%$, hydrochlorothiazide $-20 \%$. As for statins, simvastatin and atorvastatin were taken by $65 \%$ and $35 \%$ of patients, respectively.

Changes of 6-minute walk-test distance. Initially distances of 6-minute walk-test were comparable in the both groups: Me $[10 \% ; 90 \%]=300[100 ; 500] \mathrm{m}$ (Fig. 1).

Both groups demonstrated augmentation of the distance by the end of the follow-up as compared to baseline. Group 1 showed significantly higher augmentation of the distance than group $2(p<0.05)$ after 1,2 and 3 years of the follow-up.

Changes of CHF FC. Table 1 presents initial distribution of patients in accordance with CHF FC. Among patients of the first group FC I was in 15 (14.2\%) patients, FC II - in 25 (23.5\%), FC III - in 44 (41.5\%), FC IV - in 22 (20.8\%) patients. Among the second group FCI was in $13(12.4 \%)$ patients, FC II - in 27 (25.7\%), FC III - in 45 (42.8\%), FCIV - in 20 (19\%) patients. In other words, $62.3 \%$ pa-

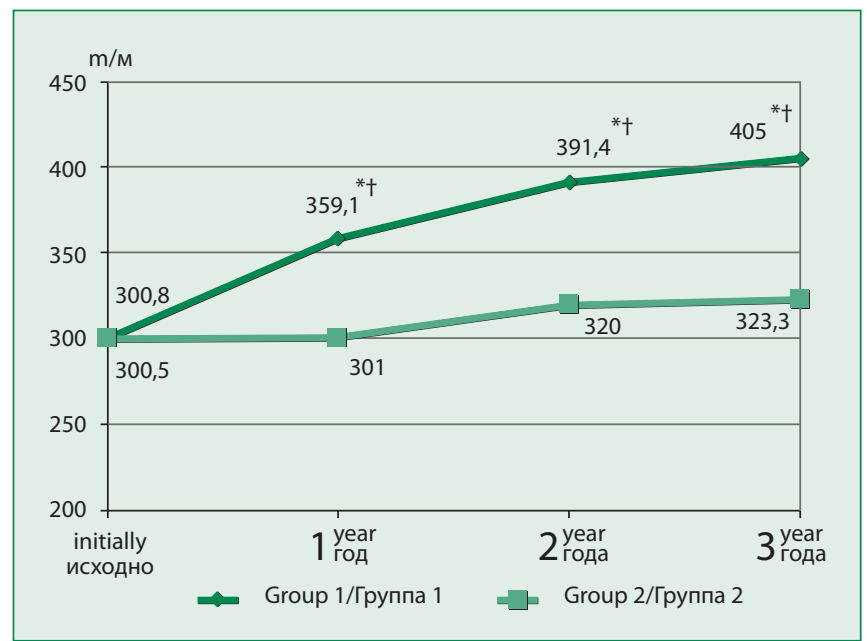

Figure 1. Dynamics of 6-minute walk-test distance in $\mathrm{CHF}$ patients in the groups of active and conventional management

Рис. 1. Динамика дистанции теста 6-минутной ходьбы у больных ХСН в группах активного и стандартного ведения

* - $\mathrm{p}<0.05$ between the groups 1 and 2 / по сравнению с противоположной группой;

$\dagger-p<0.05$ compared with the baseline values / по сравнению с исходными значениями
- 10\%, гипотиазид - 20\%. Статины были также представлены группой симвастатина (65\%) и аторвастатина (35\%).

Динамика дистанции теста 6-минутной ходьбы. Исходно дистанции, преодолеваемые пациентами в ходе теста 6-минутной ходьбы, были сопоставимы в обеих группах: Ме[10\%;90\%]=300[100;500] м (рис. 1).

В обеих группах к концу периода наблюдения произошло увеличение дистанции теста 6-минутной ходьбы по сравнению с исходным уровнем. В группе 1 прирост дистанции в ходе теста 6 -минутной ходьбы был значимо выше, чем в группе 2, через 1, 2 и 3 года наблюдения $(p<0,05)$.

Динамика ФКХСН. Исходное распределение пациентов исследуемых групп по ФК ХСН приведено в табл. 1. В первой группе I ФК был у 15 (14,2\%) больных; II ФК - y 25 (23,5\%); III ФK - y 44 (41,5\%); IV ФK - y 22 $(20,8 \%)$ больных. Во второй группе I ФК был у 13 $(12,4 \%)$ больных; II ФК - у 27 (25,7\%); III ФК - у 45 $(42,8 \%)$; IV ФК - у 20 (19\%) пациентов. Т.е. в первой группе 62,3\% и во второй группе 61,8\% обследуемых в начале исследования имели прогностически более неблагоприятный III-IV ФК XCH. K третьему году наблюдения распределение больных по ФК ХСН изменилось. В первой группе І ФК был у 19 (24,3\%) больных; II ФК - у 22 (28,2\%); III ФК - у 23 (29,4\%); IV ФК - у $14(17,9 \%)$ больных. Во второй группе I ФК был у 5 (8,3\%) больных; ІІ ФК - у 10 (16,6\%); ІІІ ФК - у 27 (45\%); IV ФК - у $19(31,6 \%)$ пациентов. Таким образом, к третьему году наблюдения в группе активного ведения доля больных, имеющих III-IV ФК XCH, снизилась до 47,3\%. В группе стандартного ведения тенденция обратная - до 76,6\% увеличилась доля пациентов с прогностически неблагоприятными ФК ХСН.

Изменения ЭхоКГ показателей. Динамика ЭхоКГ показателей у больных XСН групп активного и стандартного ведения представлена в табл. 3. Пациенты обеих групп в начале исследования были сопоставимы по основным ЭхоКГ показателям. У них имелись умеренная дилатация полостей предсердий и желудочков, снижение ФВ ЛЖ до 40\%, эксцентрическая гипертрофия миокарда левого желудочка (ЛЖ), сопровождающаяся увеличением индекса массы миокарда левого желудочка (ИММ ЛЖ), наличие 1-2 степени легочной гипертензии.

В первой группе за время наблюдения изменения размеров предсердий и желудочков, ФВ ЛЖ, а также ИММ Лж были статистически незначимыми $(\mathrm{p}>0,05)$. При этом через 3 года наблюдения отмечено снижение $(p<0,05)$ уровня САД в легочной артерии (СДЛА).

У пациентов второй группы через 3 года отмечено значимое $(p<0,05)$ увеличение линейных и объемных размеров камер сердца, толщины задней стенки ЛЖ, ИММ ЛЖ, СДЛА, а также значимое сни- 
tients of the first group and $61.8 \%$ patients of the second group had severe FC III-IV at the beginning of the study. CHF FC distribution had changed by the third year of the follow-up. In the first group: FC I was in 19 (24.3\%) patients, FC II - in 22 (28.2\%), FC III - in 23 (29.4\%), FC IV - in $14(17.9 \%)$ patients. In the second group FCI was in $5(8.3 \%)$ patients, FC II - in $10(16.6 \%), F C ~ I I I-$ in 27 (45\%), FC IV - in 19 (31.6\%) patients. Consequently, a number of patients with FC III-IV in the group of active management decreased to $47.3 \%$ by the third year of the follow-up. Group of conventional management had reverse trend: share of patients with prognostic unfavorable CHF FC had increased up to $76.6 \%$.

Changes of echocardiograpic parameters. Changes of echocardiograpic parameters in the groups of active and conventional management are presented in Table 3. Initially patients of the both groups were comparable by the main echocardiograpic indices. They had moderate atrium and ventricle dilatation, LV EF reduction to $40 \%$, eccentric hypertrophy of LV myocardium with increase of LV myocardium mass index (LV MMI), pulmonary hypertension of I-II degree.

Atrium and ventricle dimensions, LV EF and LV MMI had changed statistically not significant $(p>0.05)$ in the first group. Pulmonary artery systolic pressure (PASP) decreased after 3 years of the follow-up $(p<0.05)$. жение ФВ ЛЖ $(p<0,05)$ как по сравнению с исходными параметрами, так и с аналогичными показателями группы 1.

Динамика NT-proBNP. Исходно пациенты обеих групп были сопоставимы по уровню NT-proBNP (рис. 2). В группе 1 в процессе наблюдения отмечается незначимое снижение NT-proBNP со 110 пг/мл до 80 пг/мл $(p>0,05)$. У пациентов группы 2 при динамическом наблюдении отмечено существенное увеличение NT-proBNP $(p<0,05)$, превышающее этот показатель у больных группы 1.

Изменения лабораторных показателей. Исходно пациенты обеих группы были сопоставимы по основным лабораторным показателям и СКФ (табл. 4).

В первой группе отмечалось недостоверное снижение уровня общего холестерина (OXC) до 4,7 ммоль/л, холестерина липопротеинов низкой плотности (ХС ЛНП) до 4,01 ммоль/л.

В группе 2 имелась обратная тенденция к увеличению ОХС и ХС ЛНП (p>0,05). Через 3 года наблюдения данные показатели у пациентов второй группы были значимо выше $(p<0,05)$, чем у пациентов группы 1.

Таким образом, более адекватная терапия статинами у пациентов группы активного ведения приводила к снижению ОХС и ХС ЛПН.

Table 3. Changes of echocardiographic indices in CHF patients in the groups of active and conventional management Таблица 3. Динамика ЭхоКГ показателей у больных ХCH в группах активного и стандартного ведения

\begin{tabular}{|c|c|c|c|c|c|c|c|c|}
\hline \multirow{2}{*}{$\begin{array}{l}\text { Index } \\
\text { Показатели }\end{array}$} & \multicolumn{4}{|c|}{ Group 1 / Группа 1} & \multicolumn{4}{|c|}{ Group 2 / Группа 2} \\
\hline & $\begin{array}{l}\text { Initially } \\
\text { Исходно }\end{array}$ & $\begin{array}{c}\text { 1-st year } \\
1 \text { rod }\end{array}$ & $\begin{array}{l}2-d \text { year } \\
2 \text { rода }\end{array}$ & $\begin{array}{c}\text { 3-d year } \\
3 \text { года }\end{array}$ & $\begin{array}{c}\text { Initially } \\
\text { Исходно }\end{array}$ & $\begin{array}{l}\text { 1-st year } \\
1 \text { roд }\end{array}$ & $\begin{array}{l}\text { 2-d year } \\
2 \text { года }\end{array}$ & $\begin{array}{l}\text { 3-d year } \\
3 \text { года }\end{array}$ \\
\hline LV SV, ml / УО ЛЖ, мл & $77.6 \pm 17$ & $80.4 \pm 15.3$ & $80.3 \pm 16.3$ & $80.6 \pm 16.1$ & $78.8 \pm 17.4$ & $81.5 \pm 19$ & $85.1 \pm 16.2$ & $87 \pm 17^{*+}$ \\
\hline LA ESD, cm / КСР ЛП, см & $4.36 \pm 0.44$ & $4.41 \pm 0.38$ & $4.41 \pm 0.34$ & $4.41 \pm 0.35$ & $4.40 \pm 0.4$ & $4.56 \pm 0.38^{*+}$ & $4.78 \pm 0.62^{*+}$ & $4.84 \pm 0.64^{*+1}$ \\
\hline LV ESD, cm / КСР ЛЖ, см & $4.9 \pm 0.89$ & $5.08 \pm 0.9$ & $5.16 \pm 0.84$ & $5.25 \pm 0.81$ & $5.04 \pm 0.89$ & $5.27 \pm 0.91$ & $5.53 \pm 0.84^{*+}$ & $5.71 \pm 0.8^{*+}$ \\
\hline LV EDD, cm / КДР ЛЖ, см & $6.2 \pm 0.79$ & $6.3 \pm 0.88$ & $6.36 \pm 0.9$ & $6.44 \pm 0.77$ & $6.23 \pm 0.91$ & $6.51 \pm 0.84$ & $6.74 \pm 0.83^{*+}$ & $6.9 \pm 0.82^{*+}$ \\
\hline LV ESV, ml / КСО ЛЖ, мл & $118 \pm 51$ & $125 \pm 58.3$ & $132 \pm 51.1$ & $134 \pm 50.8$ & $120 \pm 50.4$ & $135 \pm 59$ & $157 \pm 59^{* \dagger}$ & $170 \pm 50^{*+}$ \\
\hline LV EDV, ml / КДО ЛЖ, мл & $201 \pm 58$ & $209 \pm 63.2$ & $216 \pm 60.1$ & $218 \pm 61.8$ & $202 \pm 60.4$ & $219 \pm 64$ & $243 \pm 66^{* \dagger}$ & $258 \pm 65^{*+}$ \\
\hline LV EF/ФВ ЛЖ, \% & $40.4 \pm 7.5$ & $40 \pm 7.4$ & $38.7 \pm 7.3$ & $38.1 \pm 6.9$ & $39.8 \pm 7.4$ & $38.6 \pm 7.5$ & $35.6 \pm 7.2^{*+}$ & $35.1 \pm 6.4^{*+}$ \\
\hline $\begin{array}{l}\text { IVS thickness, mm } \\
\text { Толщина МЖП, мм }\end{array}$ & $1.07 \pm 0.26$ & $1.09 \pm 0.24$ & $1.03 \pm 0.26$ & $1.04 \pm 0.27$ & $1.08 \pm 0.3$ & $1.09 \pm 0.32$ & $1.09 \pm 0.24$ & $1.07 \pm 0.28$ \\
\hline $\begin{array}{l}\text { LV PW thickness, mm } \\
\text { Толщина ЗС ЛЖ, мм }\end{array}$ & $1.09 \pm 0.2$ & $1.07 \pm 0.21$ & $1.03 \pm 0.18$ & $1.02 \pm 0.17$ & $1.08 \pm 0.23$ & $1.14 \pm 0.22$ & $1.28 \pm 0.16^{* \dagger}$ & $1.29 \pm 0.16^{*+}$ \\
\hline LV MMI, g/m²/ ИММ ЛЖ, г/M² & $153 \pm 47.7$ & $156 \pm 48.4$ & $157 \pm 48$ & $156 \pm 40.8$ & $154 \pm 47.4$ & $172 \pm 41.9$ & $186 \pm 40.6^{*+}$ & $194 \pm 48.7^{*+}$ \\
\hline RA ESD, cm / КCP ПП, сM & $4.05 \pm 0.52$ & $4.2 \pm 0.44$ & $4.18 \pm 0.5$ & $4.16 \pm 0.55$ & $4.07 \pm 0.54$ & $4.47 \pm 0.4^{* \dagger}$ & $4.63 \pm 0.63^{*+}$ & $4.66 \pm 0.52^{*+}$ \\
\hline RVESD, cm / КCР ПЖ, сM & $2.9 \pm 0.55$ & $2.99 \pm 0.22$ & $2.95 \pm 0.21$ & $2.96 \pm 0.29$ & $2.8 \pm 0.4$ & $3.21 \pm 0.31^{*+}$ & $3.3 \pm 0.27^{*+}$ & $3.35 \pm 0.33^{*+1}$ \\
\hline $\begin{array}{l}\text { RV wall thickness, mm } \\
\text { Толщина стенки ПЖ, мм }\end{array}$ & $0.59 \pm 0.08$ & $0.58 \pm 0.05$ & $0.57 \pm 0.04$ & $0.57 \pm 0.03$ & $0.59 \pm 0.07$ & $0.6 \pm 0.08$ & $0.61 \pm 0.07^{* \dagger}$ & $0.6 \pm 0.04^{*+}$ \\
\hline $\begin{array}{l}\text { PASP, mm Hg } \\
\text { СДЛА, мм рт. ст. }\end{array}$ & $49.8 \pm 11$ & $45 \pm 9.3$ & $45.2 \pm 8.8$ & $45.3 \pm 8.1^{\dagger}$ & $49.7 \pm 11.2$ & $49.9 \pm 9.5^{* \dagger}$ & $54.1 \pm 11.2^{*+}$ & $57.4 \pm 11.3^{*+}$ \\
\hline
\end{tabular}

Data are presented as $\mathrm{M} \pm \mathrm{SD} ;{ }^{*}-p<0.05$ between the groups 1 and $2 ; \uparrow-p<0.05$ as compared to the initial values

Данные представлены в виде M \pm SD; *-p<0,05 между группами 1 и 2; $\uparrow$-p $<0,05$ по сравнению с исходными значениями

SV-stroke volume, ESD-end systolic dimension, EDD-end diastolic dimension, ESV-end systolic volume, EDV-end diastolic volume, IVS-interventricular septum, PW-posterior wall, MMI-myocardium mass index, LV-left ventricle, LA-left atrium, RA-right atrium, RV-right ventricle, PASP-pulmonary artery systolic pressure

УО-ударный объем, КСР-конечный систолический размер, КДР-конечный диастолический размер, КСО-конечный систолический объем, КДО-конечный диастолический объем, МЖП-межжелудочковая перегородка, ЗС-задняя стенка, ИММ-индекс массы миокарда, ЛЖ-левый желудочек, ЛП-левое предсердие, ПП-правое предсердие,

ПЖ-правый желудочек, СДЛА-систолическое давление в легочной артерии 


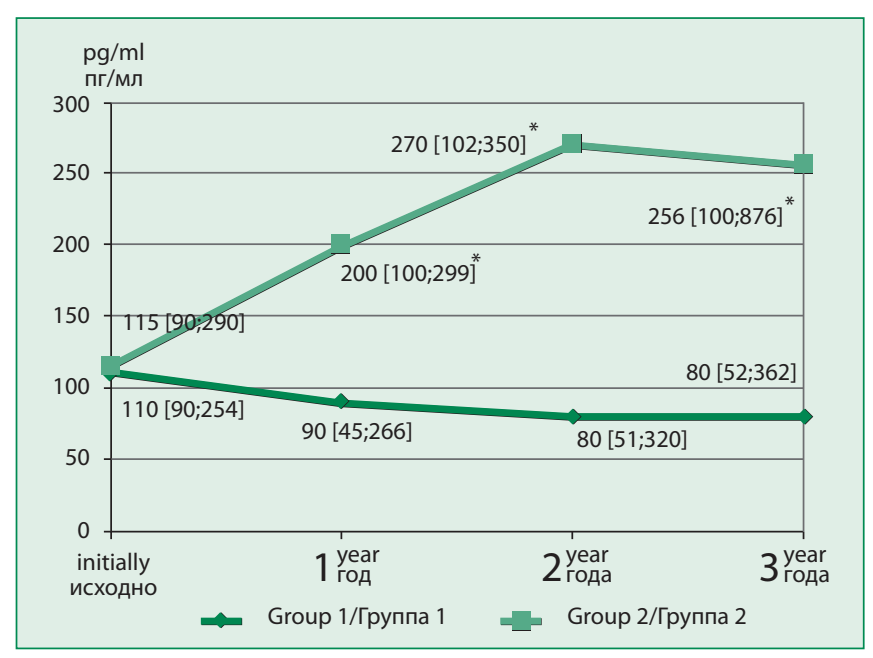

Figure 2. Changes of NT- proBNP in CHF patients in the groups of active and conventional management

Рис. 2. Динамика NT-proBNP у больных XCH в группах активного и стандартного ведения

Data are presented as Me [10\%; 90\%]/ Данные представлены в виде Ме [10\%; 90\%];

* - $\mathrm{p}<0.05$ between the groups 1 and 2 / по сравнению с

противоположной группой

Patients of the second group showed significant $(p<0.05)$ increase in heart chambers linear and volumetric dimensions, LV posterior wall thickness, LV MMI, PASP and significant decrease in LV EF $(p<0.05)$ as compared to both baseline parameters and to these indices of the first group.
По уровню холестерина липопротеинов высокой плотности (ХС ЛВП), триглицеридов, гемоглобина, мочевой кислоты, креатинина и СКФ значимых различий не выявлено.

В течение наблюдения у пациентов обеих групп отмечено увеличение ВчСРБ ( $>>0,05)$. Динамика ВчСРБ у больных обеих группах на протяжении трех лет сопоставима $(p>0,05)$. Однако верхняя граница изменения признака у пациентов группы 2 была больше, чем у больных группы активного наблюдения.

Динамика АД и ЧСС. В течение трех лет наблюдения в группе 1 отмечалось снижение САД и ДАД, не достигавшее статистической значимости ( $>>0,05)$ (табл. 5). В группе 2 имелась обратная тенденция, к третьему году САД и ДАД повысились по сравнению с исходными данными $(p>0,05)$. Указанные тенденции изменения уровня АД способствовали тому, что к третьему году наблюдения САД и ДАД у пациентов группы 1 были значимо ниже $(p<0,05)$, чем у пациентов группы 2.

За все время наблюдения у пациентов группы 1 установлено значимое $(p<0,05)$ снижение чСС как по сравнению с исходными данными, так и с ЧСС у больных группы 2. Динамики ЧСС у пациентов группы 2 не выявлено.

Частота развития сердечно-сосудистых осложнений. В группе активного ведения ССО в первый год развились у 25 (24\%) пациентов; во второй год - у 34 (34\%); в третий - у 39 (50\%) больных (табл. 6). Из

Table 4. Laboratory indices dynamics in CHF patients in the groups of active and conventional management Таблица 4. Динамика лабораторных показателей у больных ХCH в группах активного и стандартного ведения

\begin{tabular}{|c|c|c|c|c|c|c|c|c|}
\hline \multirow{2}{*}{$\begin{array}{c}\text { Index } \\
\text { Показатели }\end{array}$} & \multicolumn{4}{|c|}{ Group 1 / Группа 1} & \multicolumn{4}{|c|}{ Group 2 / Группа 2} \\
\hline & $\begin{array}{l}\text { Initially } \\
\text { Исходно }\end{array}$ & $\begin{array}{c}\text { 1-st year } \\
1 \text { roд }\end{array}$ & $\begin{array}{c}\text { 2-d year } \\
2 \text { rода }\end{array}$ & $\begin{array}{c}3-\text { d year } \\
3 \text { rода }\end{array}$ & $\begin{array}{c}\text { Initially } \\
\text { Исходно }\end{array}$ & $\begin{array}{c}\text { 1-st year } \\
1 \text { roд }\end{array}$ & $\begin{array}{l}\text { 2-d year } \\
2 \text { года }\end{array}$ & $\begin{array}{l}\text { 3-d year } \\
3 \text { года }\end{array}$ \\
\hline $\begin{array}{l}\mathrm{TCS}, \mathrm{mmol} / \mathrm{l} \\
\text { ОХС, ммоль/л }\end{array}$ & $5.35 \pm 1.32$ & $5.3 \pm 1.3$ & $4.71 \pm 0.6$ & $4.7 \pm 0.61$ & $5.4 \pm 1.4$ & $5.51 \pm 1.12$ & $5.63 \pm 1.3^{*}$ & $5.62 \pm 0.9^{*}$ \\
\hline $\begin{array}{l}\text { LDL CS, mmol/l } \\
\text { ХС ЛНП, ммоль/л }\end{array}$ & $4.25 \pm 0.81$ & $4.2 \pm 0.78$ & $4.15 \pm 0.78$ & $4.01 \pm 0.82$ & $4.3 \pm 0.8$ & $4.3 \pm 0.81$ & $4.35 \pm 0.9$ & $4.35 \pm 0.88^{*}$ \\
\hline $\begin{array}{l}\mathrm{HDL} \mathrm{CS,} \mathrm{mmol/l} \\
\text { ХС ЛВП, ммоль/л }\end{array}$ & $1.14 \pm 0.48$ & $0.94 \pm 0.4$ & $0.9 \pm 0.4$ & $0.94 \pm 0.14$ & $1.15 \pm 0.61$ & $0.9 \pm 0.62$ & $0.85 \pm 0.62$ & $0.9 \pm 0.17$ \\
\hline $\begin{array}{l}\mathrm{TG}, \mathrm{mmol} / \mathrm{l} \\
\mathrm{T \Gamma}, \text { ммоль/л }\end{array}$ & $1.41 \pm 0.68$ & $1.41 \pm 0.65$ & $1.48 \pm 0.7$ & $1.48 \pm 0.68$ & $1.41 \pm 0.68$ & $1.48 \pm 0.71$ & $1.51 \pm 0.88$ & $1.59 \pm 0.88$ \\
\hline $\begin{array}{l}\text { Hemoglobin, g/l } \\
\text { Гемоглобин,г/л }\end{array}$ & $145 \pm 18$ & $145 \pm 14.9$ & $145 \pm 17$ & $140 \pm 17.9$ & $144 \pm 14.1$ & $141 \pm 15.8$ & $140 \pm 16$ & $138 \pm 16.2$ \\
\hline $\begin{array}{l}\text { Uric acid, mumol/l } \\
\text { Мочевая кислота, } \\
\text { мкмоль/л }\end{array}$ & $264 \pm 90$ & $314 \pm 92$ & $320 \pm 89$ & $329 \pm 92.6$ & $270 \pm 95.4$ & $321 \pm 93.6$ & $331 \pm 93.1$ & $335 \pm 100.6$ \\
\hline $\begin{array}{l}\text { Creatinine, mumol/l } \\
\text { Креатинин, мкмоль/л }\end{array}$ & $98 \pm 16$ & $95 \pm 15.6$ & $99 \pm 16.5$ & $99 \pm 16.6$ & $100 \pm 17.6$ & $100 \pm 17.7$ & $101 \pm 18.3$ & $101 \pm 17.6$ \\
\hline $\begin{array}{l}\mathrm{GFR}, \mathrm{ml} / \mathrm{min} / \mathrm{m}^{2} \\
\mathrm{CKФ}, \mathrm{M} / \mathrm{Mин} / \mathrm{M}^{2}\end{array}$ & $85.4 \pm 18.8$ & $84.4 \pm 20$ & $82.4 \pm 19.9$ & $81.6 \pm 20.9$ & $85.6 \pm 19.8$ & $82.6 \pm 17.3$ & $79.1 \pm 14.9$ & $77.6 \pm 13$ \\
\hline $\begin{array}{l}\text { SsCRP, g/l } \\
\text { ВчСРБ, г/л }\end{array}$ & $1.4[0.7 ; 8.3]$ & $2.3[0.9 ; 12.4]$ & $3.0[0.5 ; 12.3]$ & $3.0[0.6 ; 12]$ & $1.5[0.7 ; 10.4]$ & $2.1[0.9 ; 17.2]$ & $3.2[1 ; 30]$ & $3.2[1 ; 30]$ \\
\hline
\end{tabular}

Data are presented as $\mathrm{M} \pm \mathrm{SD}$ and $\mathrm{Me}[10 \% ; 90 \%] ;{ }^{*}-p<0.05$ between the groups 1 and 2

Данные представлены в виде M \pm SD и Me[10\%; 90\%]; * - p<0,05 между группами 1 и 2

LDL CS-low density lipoproteins cholesterol, HDL CS-high-density lipoproteins cholesterol, TG-triglycerides, GFR-glomerular filtration rate

ХС ЛНП-холестерин липопротеинов низкой плотности, ХС ЛВП-холестерин липопротеинов высокой плотности, ТГ-триглицериды, СКФ-скорость клубочковой фильтрации 
Changes of NT-proBNP. Initially patients of the both groups were comparable by NT-proBNP level (Fig.2). Not significant $(p>0.05)$ reduction in NT-proBNP level from $110 \mathrm{pg} / \mathrm{ml}$ to $80 \mathrm{pg} / \mathrm{ml}$ during the follow-up was revealed in the first group. The patients of the second group showed significant increase in NT-proBNP level $(p<0.05)$ that exceeded this in the first group.

Changes of laboratory indices. Initially patients of the both groups were comparable by the main laboratory indices and GFR (Table 4).

The first group showed insignificant decrease in total cholesterol (TCS) level to $4.7 \mathrm{mmol} / \mathrm{l}$ and cholesterol of low density lipoproteins (LDLCS) to $4.01 \mathrm{mmol} /$.

The second group demonstrated the reverse tendency: TCS and LDL CS levels increased ( $p>0.05)$. These indices were significantly higher in patients of the second group $(p<0.05)$ than these in patients of the first one 3 years later.

Therefore, more adequate treatment with statins in the group of active management contributed to reduction in TCS and LDL CS levels.

Levels of high-density lipoproteins cholesterol (HDL CS), triglycerides, hemoglobin, uric acid, creatinine as well as GFR did not distinguish significantly in the groups during follow-up.

Level of SsCRP increased in the both groups within the follow-up ( $p>0.05$ ). Variations of SsCRP levels in the both groups were comparable over the period of three years $(p>0.05)$. However, upper boundary of index variation was higher in the second group patients as compared to patients of active management group.

Dynamics of BP and HR. For three years of the follow-up the first group patients had insignificant SBP and DBP decrease $(p>0.05)$ (Table 5$)$. Patients of the second group showed the reverse trend: SBP and DBP increased by the third year of the follow-up as compared to the baseline общего числа ССО практически у половины больных за время наблюдения имелась декомпенсация XСH. Ухудшение течения ХСН в первый год было у 15 (14\%) больных; во второй - у 19 (19\%); в третий у 20 (25\%) пациентов. Повторный инфаркт миокарда в первый год развился у 3 (3\%); во второй - у 7 (7\%); в третий - у 9 (12\%) пациентов. Летальный исход наступил в первый год у 7 (7\%); во второй - у 8 (8\%); в третий - у 10 (13\%) больных.

В первой группе больных за время наблюдения отмечена тенденция к увеличению числа ССО. Так, через 3 года наблюдения каждый второй пациент имел ухудшение сердечной деятельности, каждый четвертый пациент был госпитализирован по поводу декомпенсации XCH, у каждого восьмого больного развивался повторный инфаркт миокарда или был летальный исход.

В группе 2 ССО в первый год развились у 53 (51\%) пациентов; во второй год - у 56 (64\%) больных; в третий год - у 60 (100\%) обследуемых (табл. 6).

у большинства больных отмечена декомпенсация XCH. Ухудшение течения XCH в первый год было у 33 (32\%) пациентов; во второй - у 33 (38\%); в третий у 34 (57\%) больных. Повторный инфаркт миокарда в первый год развился у 9 (9\%) пациентов; во второй - у 11 (13\%); в третий - у 11 (18\%) больных. Летальный исход наступил в первый год у 11 (11\%) пациентов; во второй - у 12 (14\%); в третий - у 15 (25\%) больных.

В группе 2 динамика ССО была более тревожная, чем в группе 1: у половины больных в первый и второй годы и у каждого пациента в течение третьего года наблюдения отмечены ССО. К окончанию наблюдения каждый второй пациент был госпитализирован по поводу декомпенсации ХCH, у каждого пятого больного развился повторный инфаркт миокарда, каждый четвертый пациент умер.

Table 5. BP and HR dynamics in CHF patients in the groups of active and conventional management

Таблица 5. Динамика показателей АД и ЧСС у больных ХСН в группах активного и стандартного ведения

\begin{tabular}{|c|c|c|c|c|c|c|c|c|}
\hline \multirow{2}{*}{$\begin{array}{c}\text { Index } \\
\text { Показатели }\end{array}$} & \multicolumn{4}{|c|}{ Group 1 / Группа 1} & \multicolumn{4}{|c|}{ Group 2 / Группа 2} \\
\hline & $\begin{array}{c}\text { Initially } \\
\text { Исходно }\end{array}$ & $\begin{array}{c}1 \text {-st year } \\
1 \text { roд }\end{array}$ & $\begin{array}{c}\text { 2-d year } \\
2 \text { года }\end{array}$ & $\begin{array}{c}\text { 3-d year } \\
3 \text { года }\end{array}$ & $\begin{array}{c}\text { Initially } \\
\text { Исходно }\end{array}$ & $\begin{array}{c}1 \text {-st year } \\
1 \text { roд }\end{array}$ & $\begin{array}{c}\text { 2-d year } \\
2 \text { года }\end{array}$ & $\begin{array}{c}\text { 3-d year } \\
3 \text { года }\end{array}$ \\
\hline \multirow[t]{2}{*}{ SВР, mm Hg / САД, мм рт.ст. } & $\begin{array}{c}127 \\
{[100 ; 159]}\end{array}$ & $\begin{array}{c}125 \\
{[105 ; 148]}\end{array}$ & $\begin{array}{c}125 \\
{[105 ; 140]}\end{array}$ & $\begin{array}{c}120 \\
{[100 ; 140]^{*}}\end{array}$ & $\begin{array}{c}127 \\
{[100 ; 159]}\end{array}$ & $\begin{array}{c}125 \\
{[105 ; 148]}\end{array}$ & $\begin{array}{c}125 \\
{[105 ; 140]} \\
\end{array}$ & $\begin{array}{c}120 \\
{[100 ; 140]}\end{array}$ \\
\hline & $\begin{array}{c}126 \\
{[100 ; 160]}\end{array}$ & $\begin{array}{c}139 \\
{[100 ; 150]}\end{array}$ & $\begin{array}{c}139 \\
{[100 ; 152]}\end{array}$ & $\begin{array}{c}146 \\
{[112 ; 170]}\end{array}$ & $\begin{array}{c}126 \\
{[100 ; 160]}\end{array}$ & $\begin{array}{c}139 \\
{[100 ; 150]}\end{array}$ & $\begin{array}{c}139 \\
{[100 ; 152]}\end{array}$ & $\begin{array}{c}146 \\
{[112 ; 170]}\end{array}$ \\
\hline \multirow[t]{2}{*}{ DBP, mm Hg / ДАД, мм рт. ст. } & $\begin{array}{c}75 \\
{[60 ; 100]}\end{array}$ & $\begin{array}{c}75 \\
{[60 ; 90]} \\
\end{array}$ & $\begin{array}{c}75 \\
{[60 ; 95]} \\
\end{array}$ & $\begin{array}{c}70 \\
{[60 ; 90]^{*}}\end{array}$ & $\begin{array}{c}75 \\
{[60 ; 100]}\end{array}$ & $\begin{array}{c}75 \\
{[60 ; 90]} \\
\end{array}$ & $\begin{array}{c}75 \\
{[60 ; 95]}\end{array}$ & $\begin{array}{c}70 \\
{[60 ; 90]^{*}}\end{array}$ \\
\hline & $\begin{array}{c}75 \\
{[60 ; 100]} \\
\end{array}$ & $\begin{array}{c}77 \\
{[70 ; 100]}\end{array}$ & $\begin{array}{c}75 \\
{[70 ; 100]} \\
\end{array}$ & $\begin{array}{c}85 \\
{[70 ; 100]}\end{array}$ & $\begin{array}{c}75 \\
{[60 ; 100]} \\
\end{array}$ & $\begin{array}{c}77 \\
{[70 ; 100]}\end{array}$ & $\begin{array}{c}75 \\
{[70 ; 100]} \\
\end{array}$ & $\begin{array}{c}85 \\
{[70 ; 100]} \\
\end{array}$ \\
\hline \multirow[t]{2}{*}{$\mathrm{HR} / 4 \mathrm{CC}$} & $\begin{array}{c}71 \\
{[60 ; 80]}\end{array}$ & $\begin{array}{c}64 \\
{[58 ; 76]^{*+}}\end{array}$ & $\begin{array}{c}64 \\
{[51 ; 76]^{\dagger}}\end{array}$ & $\begin{array}{c}64 \\
{[51 ; 72]^{*+}}\end{array}$ & $\begin{array}{c}71 \\
{[60 ; 80]}\end{array}$ & $\begin{array}{c}64 \\
{[58 ; 76]^{*+}}\end{array}$ & $\begin{array}{c}64 \\
{[51 ; 76]^{+}}\end{array}$ & $\begin{array}{c}64 \\
{[51 ; 72]^{*+}}\end{array}$ \\
\hline & $\begin{array}{c}72 \\
{[60 ; 80]}\end{array}$ & $\begin{array}{c}70 \\
{[60 ; 92]}\end{array}$ & $\begin{array}{c}67 \\
{[58 ; 75]}\end{array}$ & $\begin{array}{c}70 \\
{[60 ; 80]}\end{array}$ & $\begin{array}{c}72 \\
{[60 ; 80]}\end{array}$ & $\begin{array}{c}70 \\
{[60 ; 92]}\end{array}$ & $\begin{array}{c}67 \\
{[58 ; 75]}\end{array}$ & $\begin{array}{c}70 \\
{[60 ; 80]}\end{array}$ \\
\hline
\end{tabular}

Data are presented as Me [10\%; 90\%]; ${ }^{*}-p<0.05$ between the groups 1 and $2 ;+-p<0.05$ as compared to the initial values

Данные представлены в виде Ме[10\%; 90\%]; *-р<0,05 по сравнению спротивоположной группой; †-р<0,05 по сравнению с исходными значениями 
data ( $p>0.05)$. Thanks to these tendencies SBP and DBP levels in patients of the first group were significantly lower $(p<0.05)$ than these in patients the second group by the third year of the follow-up.

Over the whole follow-up period the first group patients showed significant $(p<0.05)$ decrease in $H R$ as compared to both initial data and HR in the second group patients. The second group patients did not have any dynamics in HR over the follow-up.

The frequency of cardiovascular complications occurrence. In the group of active management CVC manifested in 25 (24\%) patients during the first year of the follow-up, in $34(34 \%)$ - during the second one and in 39 (50\%) patients during the third year (Table 6). CHF exacerbation accounted for about a half of the total number of CVC. 15 (14\%) patients had CHF exacerbation during the first year, 19 (19\%) - during the second one and 20 (25\%) patients - during the third year of the follow-up. Myocardial re-infarction occurred in $3(3 \%)$ patients during the first year, in $7(7 \%)$ - during the second year and in $9(12 \%)$ - during the third year of the follow-up. 7 (7\%) patients died during the first year, $8(8 \%)$ - during the second year and $10(13 \%)$ patients - during the third year of the follow-up.

A tendency to increase in CVC number was observed in the first group over the follow-up period. After three years of the follow-up every second patient had CHF exacerbation, every forth was admitted to hospital because of this reason, every eighth experienced myocardial re-infarction or died.

In the second group 53 (51\%) patients had CVC during the first year of the follow-up, 56 (64\%) - during the second one and 60 (100\%) - during the third year (Table 6).

Majority of patients experienced CHF exacerbation over the follow-up period. CHF exacerbation occurred in $33(32 \%)$ patients during the first year, in $33(38 \%)-$ during the second year and in $34(57 \%)$ - during the third year of the follow-up. 9 ( $9 \%$ ) patients had myocardial re-infarction during the first year, $11(13 \%)$ - during the second year and $11(18 \%)$ - during the third year. $11(11 \%)$ patients died during the first year, $12(14 \%)$ during the second year and 15 (25\%) - during the third year of the follow-up.
Для определения влияния различных способов ведения больных на развитие ССО были построены кривые времени наступления неблагоприятных событий (Каплана-Мейера) с анализом достоверности различий про помощи теста Log-rank. Установлено, что вероятность развития ССО у пациентов при активном ведении к третьему году наблюдения значимо $(p=0,04)$ меньше, чем у пациентов при стандартном ведении (рис. 3). Вероятность развития декомпенсации XCH у пациентов при активном ведении в течение 3 лет значимо ( $p=0,001)$ меньше, чем у больных при стандартном ведении (рис. 4). Вероятность развития повторного инфаркта миокарда у больных обеих групп существенно не различается $(p=0,21)$ (рис. 5). Напротив, вероятность развития летального исхода у больных при активном ведении к третьему году наблюдения значимо меньше $(p=0,04)$, чем y больных при стандартном ведении (рис. 6).

\section{Обсуждение}

Согласно данным российского исследования ЭПОХА-О-ХСН, больных, обратившихся в медицинские учреждения с диагнозом $X \mathrm{CH}$, лечат по самому высокому стандарту: в 87\% случаев назначаются иАПФ и в 57\% - бета-блокаторы [12]. Однако исследование ЭПОХА-ХСН, проведенное в репрезентативной выборке, показало, что эта картина обманчива и в амбулаторных условиях больные перестают принимать рекомендованную терапию. Так, частота приема иАПФ падает до 37\%, бета-блокаторов - до 15\% [13].

Проведенное нами исследование было направлено на оценку эффективности активного контроля за состоянием пациентов с XСH по сравнению со стандартной практикой ведения таких пациентов. При стандартной практике на амбулаторном этапе ингибиторы АПФ/АРА ІІ, БАБ, антагонисты альдостерона принимал только каждый второй пациент и каждый третий больной получал статины, что совпадает с данными исследования ЭПОХА-ХСН [13]. Данные этого исследования опубликованы в 2006 г., наблюдение пациентов в нашей работе проводилось с 2007 по 2010 гг., то есть в последние годы частота приема лекарственных препаратов основных групп существенно не из-

Table 6. CVC occurrence in CHF patients in the groups of active and conventional management Таблица 6. Частота развития ССО у больных ХCH в группах активного и стандартного ведения

\begin{tabular}{|c|c|c|c|c|c|c|}
\hline \multirow{2}{*}{$\begin{array}{c}\text { P Index } \\
\text { Показатели }\end{array}$} & \multicolumn{3}{|c|}{ Group 1 / Группа 1} & \multicolumn{3}{|c|}{ Group 2 / Группа 2} \\
\hline & 1-st year / 1 год & 2-d year / 2 года & 3-d year / 3 года & 1-st year / 1 год & 2-d year / 2 года & 3-d year / 3 года \\
\hline Total number of CVC / Общее число CCO, n (\%) & $25(24)$ & $34(34)$ & $39(50)$ & $53(51)$ & $56(64)$ & $60(100)$ \\
\hline CHF exacerbation / Ухудшение XСН, n (\%) & $15(14)$ & $19(19)$ & $20(25)$ & $33(32)$ & $33(38)$ & $34(57)$ \\
\hline Myocardial re-infarction / Повторный ИМ, n (\%) & $3(3)$ & $7(7)$ & $9(12)$ & $9(9)$ & $11(13)$ & $11(18)$ \\
\hline Lethal outcome / Летальный исход, n (\%) & $7(7)$ & $8(8)$ & $10(13)$ & $11(11)$ & $12(14)$ & $15(25)$ \\
\hline
\end{tabular}


The second group showed more worrisome tendency of CVC rate in comparison with the first group: a half of the patients developed CVC during the first and the second years of the follow-up and each patient - during the third year. By the end of the study every other patient was admitted to hospital due to CHF exacerbation, every fifth patient developed myocardial re-infarction and every forth patient died.

To evaluate effect of different tactics of patients management on CVC rate we plotted curves of adverse events occurrence depending on time (Kaplan-Meier) with estimation of distinctions significance by Log-rank test. It was found out that risk of CVC by the third year of the follow-up was significantly lower $(p=0.04)$ in actively managed patients than this in conventionally managed ones (Fig. 3 ). Over three years a risk of CHF exacerbation was significantly lower $(p=0.001)$ in actively managed patients than this in conventionally managed patients (Fig.4). A risk of myocardial re-infarction didn't distinguish significantly in the both groups ( $p=0.21$ ) (Fig.5). In contrast, a risk of lethal outcome by the third year of the follow-up was significantly lower in the group of active management $(p=0.04)$ than this in the group of conventional management (Fig.6).

\section{Discussion}

Russian EPOKHA-O-CHF (Epidemiology Study of Patients in European Part of Russia - Medical Consultation - CHF) study showed that patients with $\mathrm{CHF}$ receive treatment recommendation in accordance to update guidelines: ACEi are prescribed in $87 \%$ of the cases and $\beta$-blockers - in $57 \%$ [12]. However EPOKHA-CHF study demonstrated other facts - being discharged from a hospital patients give up prescribed treatment. Thus, incidence of ACEi use declines to $37 \%$ and $\beta$-blockers - to 15\% [13].

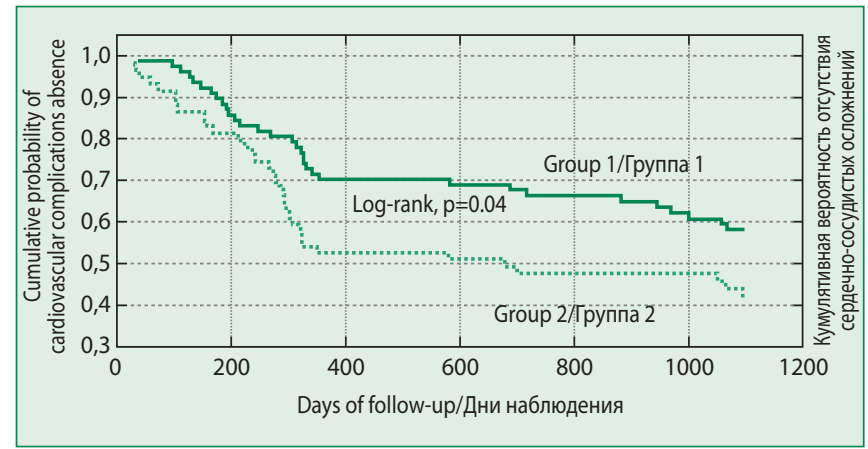

Figure 3. Kaplan-Meier curves of cumulative probability of CVC absence in the groups of active and conventional management

Рис. 3. Кривые Каплана-Мейера кумулятивной вероятности отсутствия ССО в группах активного и стандартного ведения

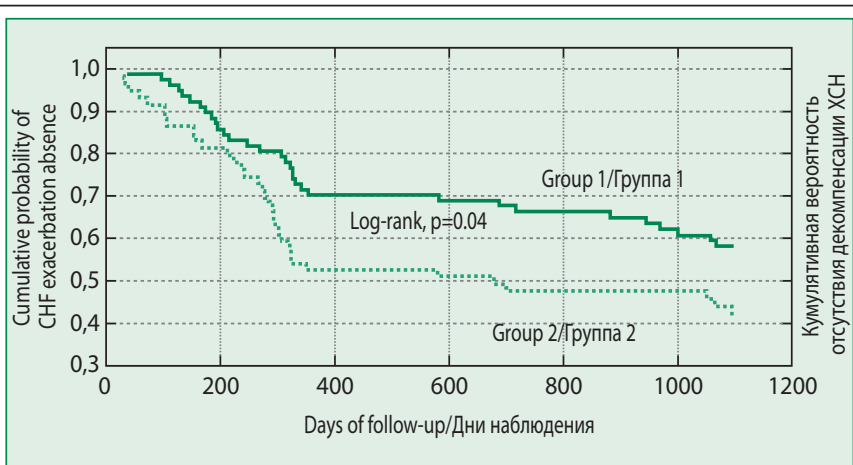

Figure 4. Kaplan-Meier curves of cumulative probabilities of $\mathrm{CHF}$ exacerbation absence in the groups of active and conventional management

Рис. 4. Кривые Каплана-Мейера кумулятивной вероятности отсутствия декомпенсации ХCH в группах активного и стандартного ведения

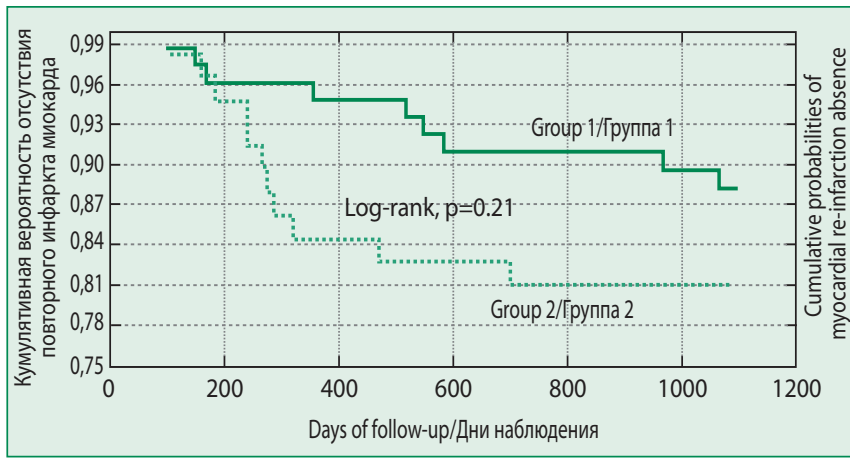

Figure 5. Kaplan-Meier curves of cumulative probabilities of myocardial re-infarction absence in the groups of active and conventional management (Log-rank, $\mathrm{p}=0.21$ )

Рис. 5. Кривые Каплана-Мейера кумулятивной вероятности отсутствия повторного инфаркта миокарда в группах активного и стандартного ведения (Log-rank, p=0,21)

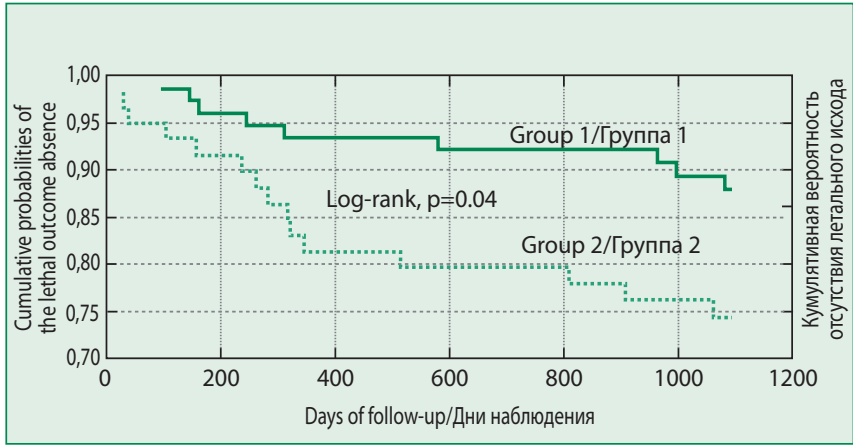

Figure 6. Kaplan-Meier curves of cumulative probabilities of the lethal outcome absence in the groups of active and conventional management

Рис. 6. Кривые Каплана-Мейера кумулятивной вероятности отсутствия летального исхода в группах активного и стандартного ведения 
Our study was aimed to evaluate an efficacy of active control of patients with CHF in comparison with conventional practice of these patients management. When managed conventionally only every other outpatient received ACEi/ARA, $\beta$-blockers and aldosterone antagonists and every third patient took statins. This data corresponds to EPOKHA-CHF study results [13] which were published in 2006. Our study was carried out from 2007 to 2010: it means that recent incidence of basic drugs taking has not changed significantly. Besides, unrecommended medicines were prescribed (atenolol), doses of ACEi/ARA and $\beta$-blockers were lower in the second group than these in the first one, while frequency of furosemide prescription was higher in the second group.

Active outpatient control facilitated to higher compliance to basic neurohormonal modulators taking in maximally tolerable doses. However statin taking rate in IHD patients with CHF didn't exceed $65 \%$ even in active management.

Actively managed patients with high compliance to ACEi therapy demonstrated heart remodeling slow-up and pulmonary artery BP reduction within three year follow-up. At the same time CHF patients of the second group, who received inadequate therapy, showed heart remodeling progression, LV EF decrease, and pulmonary artery BP raise.

Besides, active control of CHF patient's treatment prevented increase in neurohormonal mediators activity, while insufficient doses of the main drugs resulted in raise of neurohormonal activity that is unfavorable prognostic factor.

By the third year of the follow-up actively controlled patients with high compliance to ACEi, $\beta$-blockers and aldosterone antagonists taking had two times less cases of CHF exacerbation, lethal outcomes and total number of CVC than conventionally managed patients. At the same time a risk of myocardial re-infarction was similar in the both groups.

Patients of the both groups had similar training course but different outpatient management. Conventionally managed patients gave the following reasons of low therapy compliance: absence of cardiologist in residential outpatient clinic; not prescribing all essential medicines by a doctor in outpatient clinic; patient's underestimation of their state severity; loss of the knowledge received during the training.

\section{Conclusion}

The training program and active outpatient management during three years in patients with CHF improved patient compliance to pharmacotherapy and their clinical state as well as reduced a number of unfavourable events. менилась. Кроме того, назначались нерекомендованные препараты (атенолол), дозы ингибиторов АПФ/АРА ІІ, БАБ в группе 2 были ниже, чем в группе 1 , а частота назначения фуросемида выше.

Активный амбулаторный контроль способствовал более высокой приверженности приему основных нейро-гормональных модуляторов в максимально переносимых дозах. Однако прием статинов у больных XСН ишемического генеза даже при активном наблюдении не превышал $65 \%$.

У пациентов группы активного наблюдения, имеющих высокую приверженность приему ингибиторов АПФ, в течение 3 лет наблюдения отмечено замедление процессов ремоделирования сердца и снижение давления в легочной артерии. В то же время на фоне неадекватной терапии на амбулаторном этапе у пациентов XСН группы 2 прогрессировали ремоделирование миокарда, снижение ФВ ЛЖ, повышение давления в легочной артерии.

Кроме того, при активном контроле за пациентами адекватно проводимая терапия $\mathrm{XCH}$ препятствовала повышению активности нейрогормональных медиаторов, а недостаточный прием основных групп лекарственных препаратов в группе 2 способствовал нарастанию нейро-гормональной активности, что является прогностически неблагоприятным фактором.

У пациентов группы активного амбулаторного контроля, имеющих высокую приверженность приему ингибиторов АПФ, БАБ и антагонистов альдостерона, к третьему году наблюдения количество случаев декомпенсации $\mathrm{XCH}$, летальных исходов, общего числа ССО было в два раза меньше, чем в группе стандартного ведения. При этом в течение 3 лет наблюдения вероятность повторного инфаркта миокарда у пациентов обеих групп была одинакова.

Пациенты обеих групп проходили однотипное обучение, различия заключались в организации амбулаторного наблюдения. В качестве объяснения причин низкой приверженности лечению больные стандартной группы ведения высказывали следующие: отсутствие кардиолога в поликлинике, неназначение всех групп лекарственных средств врачом поликлиники, недооценка степени тяжести своего состояния пациентом, утрата знаний, полученных при обучении.

\section{Заключение}

Проводимая программа обучения и активное амбулаторное ведение в течение 3 лет у больных ХCH способствовали повышению приверженности пациентов медикаментозной терапии, улучшению клинического состояния больных и уменьшению числа неблагоприятных событий. 


\section{References/Литература}

1. Cowie M.R., Mosterd A., Wood D.A. et al. The epidemiology of heart failure. Eur Heart J 1997; 18(2): 208-225.

2. Spencer F.A, Meyer T.E., Goldberg R.J. Twenty year trends (1975-1995) in the incidence, in-hospital and long-term death rates associated with heart failure complicating acute myocardial infarction. J Am Coll Cardiol 1999; 34(5): 1378-1387.

3. Khand A., Gemmel I., Clark A.L., ClelandJ G.F. Is the prognosis of heart fail $\neg$ ure improving? J Am Coll Cardiol 2000; 36(7): 2284-2286.

4. Rumsfeld J.S., Masoudi F.A. Heart Failure disease management works / but will it succeed? Eur Heart J 2004; 25(18): 1565 - 1567

5. Stromberg A. The crucial role of patients education in heart failure. Eur J Heart Fail 2005; $7(30): 363-369$

6. Belenkov Yu.N, Ageev F.T., Banshchikov G.T. et al. Influence of specialized forms of active ambulatory management on functional status, quality of life and hemodynamic parameters of patients with severe heart failure. The results of the Russian program «Chance». Serdechnaya nedostatochnost' 2007; 8(3): 112 - 116. Russian (Беленков Ю.Н, Агеев Ф.Т., Банщиков Г.Т. и др. Влияние специализированных форм активного амбулаторного ведения на функциональный статус, качество жизни и показатели гемодинамики больных с выраженной сердечной недостаточностью. Результаты Российской программы «Шанс». Сердечная недостаточность 2007; 8(3): 112 116).

7. Gonseth J., Guallar-Castillon P. et all. The effectiveness of disease management programmes in reducing hospital re-admission in older patients with heart failure: a systematic review and meta-analysis of published reports. Eur Heart J 2004; 25(18): 1570-1595.

8. Stromberg A. The crucial role of patients education in heart failure. Eur J Heart Fail 2005; $7(30): 363-369$.
9. Guyatt G.H., Sullivan M.J., Thompson P.J. et al. The 6-minute walk: a new measure of exercise capacity in patients with chronic heart failure. Can Med Assoc J 1985; 132 (8): 919 923.

10. Levey A.S., Berg R.L., Gassman J.J. et al. Creatinine filtration, secretion and excretion during progressive renal disease. Modification of Diet in Renal Disease (MDRD) Study Group. Kidney Int Suppl 1989;27:S73-80

11. Shiller N., Osipov M.A. Clinical echocardiography. Moscow: Mir; 1993. Russian (Шиллер Н., Осипов М.А. Клиническая эхокардиография. М.: Мир; 1993)

12. Ageev F.T., Danielyan M.O., Mareev V.Yu., Belenkov Yu.N. Patients with chronic heart failure in the Russian outpatient practice: the contingent features, diagnosis and treatment (study EPOKHA-O-CHF). Serdechnaya Nedostatochnost' 2004; 5(1): 4-7. Russian (Агеев Ф.Т., Даниелян М.О., Мареев В.Ю., Беленков Ю.Н. Больные с хронической сердечной недостаточностью в российской амбулаторной практике: особенности контингента, диагностики и лечения (по материалам исследования ЭПОХА-О-ХСН). Сердечная Недостаточность 2004; 5(1): 4-7)

13. Ageev F.T., Belenkov Yu. N., Fomin I. V. et al. Prevalence of chronic heart failure in the European part of Russia - study EPOKHA-CHF. Serdechnaya Nedostatochnost' 2006;7 (1): 112-115. Russian (Агеев Ф.Т., Беленков Ю.Н., Фомин И.В. и др. Распространенность хронической сердечной недостаточности в Европейской части Российской Федерации - данные ЭПОХА-ХСН. Сердечная Недостаточность 2006;7 (1): 112-115).

Received/Поступила 21.03.2011 Accepted/Принята в печать 22.03.2011 